\title{
A prospective randomized single blind study to compare the safety and efficacy of propronolol and topiramate in migraine prophylaxis
}

\author{
Keelu Rajkumar ${ }^{1 *}$, Pothuru Anil Kumar²
}

\author{
${ }^{1}$ Department of Pharmacology, Shanthiram Medical College, Nandyal, Kurnool district, Andhra Pradesh, India \\ ${ }^{2}$ Department of Pharmacology, Viswabharathi Medical College, Kurnool, Andhra Pradesh, India
}

\author{
Received: 11 February 2021 \\ Accepted: 10 March 2021 \\ *Correspondence: \\ Dr. Pothuru Anil Kumar \\ Email: anilkumarpothuru@gmail.com
}

Copyright: (c) the author(s), publisher and licensee Medip Academy. This is an open-access article distributed under the terms of the Creative Commons Attribution Non-Commercial License, which permits unrestricted non-commercial use, distribution, and reproduction in any medium, provided the original work is properly cited.

\begin{abstract}
Background: The aim of the study was to compare the Safety and efficacy of propranolol and topiramate in migraine prophylaxis.

Methods: This was a prospective, randomized, single blind study which was conducted for six months in 100 patients of outpatient department of Neurology Government General Hospital, Guntur.

Results: Among the hundred patients fifty were allotted to group A - propranolol $40 \mathrm{mg}$ bd and fifty were allotted to group B- topiramate $25 \mathrm{mg}$ bd. statistically there is no significant differences were found between the treatment groups of Propranolol and topiramate for the reduction in mean duration and severity of migraine headaches. Both Propranolol and topiramate have $\mathrm{p}$ value $<0.001$. This shows that both propranolol and topiramate have significantly decreased in the mean duration and severity of migraine attacks. However, in the present study topiramate is slightly more efficacious in reducing the symptoms of migraine frequency per month (days), duration and severity (visual analogue scale- VAS score) from baseline at the end of six months. The decrease in frequency of migraine attacks from $10.44 \pm 4.38$ to $3.18 \pm 4.48$ i.e., $70.2 \%$ from baseline is seen with topiramate.

Conclusions: This study demonstrated that both propranolol and topiramate could significantly reduce migraine headache frequency, duration and intensity. However, compared with propranolol topiramate showed better results. topiramate $25 \mathrm{mg}$ reduced the symptoms like frequency, duration and severity of migraine attacks from base line at the end of six months but more number of adverse effects were seen in topiramate group.
\end{abstract}

Keywords: Migraine, Topiramate, Propranolol

\section{INTRODUCTION}

Headache, of all the painful states that affect humans, is undoubtedly the most frequent and common reason for seeking medical help. Migraine is a common episodic headache disorder that is characterized by attacks comprising various combinations of headache with neurological, gastrointestinal and autonomic symptoms. Studies employing the IHS (international headache society) criteria report a 1-year prevalence of migraine of 6-9\% among men and $15-17 \%$ among women. Thus the male to female ratio is $1: 2-3 .^{1}$ After gender, age is the second major factor associated with migraine prevalence. Migraine appears in all ages but reaches a peak in middle age. Options for prophylactic therapy in migraine are limited. The currently available therapies are not suitable for all patients, and some have been associated with adverse effects and contraindications in certain patient groups. The International Headache Society sub classifies migraine into migraine without aura and migraine with aura. $^{2}$ The aura being the complex of focal neurological symptoms that most often precedes or accompanies an attack. An aura sometimes occurs just before or simultaneously with the headache. The typical manifestation of this comparably distinct phase is one or more reversible focal neurological (visual, sensory, motor, language or brainstem) symptoms, developing gradually over 5-20 min and lasting for less than $60 \mathrm{~min}$ per 
symptom. ${ }^{3}$ The pain is often reported as starting in the occipital/neck regions, later becoming fronto temporal. It is throbbing in nature and aggravated by physical effort in $78-82 \%$. For up to 24 hours after the headache has subsided, they feel tired and drained or washed-out with aching muscles. Others, however, become euphoric for a period of time. ${ }^{4}$ Three areas of brain function are believed to be important in pathogenesis of migraine i.e. cerebral cortex, meningeal blood vessels and their trigeminal innervations (trigemino vascular system) and brainstem with its "head pain reception and modulation center" (the caudal nucleus of the trigeminal nerve) and its "neurotransmitter-generating centers"'(nuclei raphe magnus and dorsalis, nucleus locus coeruleus, periaqueductal gray nuclei).

\section{Objectives}

Objectives were to compare the safety and efficacy of two drugs i.e. propronolol and topiramate in migraine prophylaxis.

\section{METHODS}

\section{Study design}

This was a prospective, randomized, single blinded, interventional study conducted in Outpatient division, Neurology department, Government General Hospital, Guntur.

\section{Duration of the study}

The study was conducted for 6 months (February 2018 to July 2018).

\section{Sample size}

The sample size was 100 patients meeting the criteria of the study.

100 patients who were diagnosed as migraine were taken into the study.

\section{Diagnosis of migraine}

At least 5 attacks, the duration is $5-72 \mathrm{hrs}$, at least two attacks of unilateral head ache, moderate or severe in nature aggravated by routine physical activity with nausea with or without vomiting, photophobia. They were divided into two groups A and B by randomization, each group containing 50 patients. The study was a single blinded study. The patient did not know the drug prescribed to him/her. The label on the back of tablet strip of both the drugs was removed to conceal the identity of drug and its dose. Each patient was asked to come to O.P every 4 weeks till 6 months to check the parameters, number of migraine attacks, degree of pain and adverse effects if any and to supply the drugs.
Parameters taken in the study were: 1) body weight 2) visual analogue scale (0-4) 3) duration 4) frequency

Body weight in kgs was checked at the first visit for the both group's i.e. propronolol group and topiramate group as baseline/pretreatment. Patients were given drugs and asked to come to O. P at the end of every 4th week to check body weight up to 6 months.

\section{Ethical issues}

Patients were explained the whole procedure, advantages, probable adverse effects of drugs included in the study. After he/she accepts, an informed consent form is given in local language (Telugu) and the person is asked to sign it or put a thumb impression.

The study was approved by ethical committee, government medical college, government general hospital Guntur.

\section{Inclusion criteria}

Inclusion criteria were 1) age: 12-60 years 2) sex: both males and females 3) medical history consistent with migraine with or without aura according to HIS (international headache society) for at least one year prior to study 4) no clinically significant abnormalities on neurological exams, ECG, or clinical laboratory test result at base line

\section{Exclusion criteria}

Exclusion criteria were 1) sinus head ache, tension head ache, cluster head ache, opthalmoplegic \& hemiplegic headache 2) patients on asthma, hypertension, diabetes, psychiatric medication 3) H/O serious gastro intestinal, hepatic, renal, cardio vascular system, hematological disorders 4) smokers and alcoholics 5) pregnant and lactating mothers.

The label on the back of tablet strip of both the drugs was removed to conceal the identity of drug and its dose. Researcher knew the drug given. Drug given for Group A patients - propronolol 40mg bd up to $160 \mathrm{mg}$. Drug given for Group B patients - topiramate $25 \mathrm{mg}$ bd upto100mg (depends on the patient's response). All the 100 patients were informed to take drugs morning and evening every day.

\section{Statistical analysis}

Results of the study were analyzed statistically at the end of 6 months with the baseline parameters using paired student " $t$ " test and the significance of results was tested by taking value at $0.05 / 0.01$ sample size in each group was fifty, so the degree of freedom was 49 . After applying ' $t$ ' test the obtained $t$ value was compared with $t$ value in $t$ table at probability $0.05 / 0.01$ at 49 degrees of freedom to evaluate whether the result is significant or not. 


\section{RESULTS}

The frequency of migraine attacks is recorded for six months in both the groups, which shows the reduced frequency to $70 \%$ with topiramate when compared to propranolol. $\mathrm{P}$ value is $<0.001$ (Table 1 ).

Table 1: Change in frequency/month (days) of migraine for the patients who completed the study (values $=$ Mean \pm SD $)$.

\begin{tabular}{|lll|}
\hline Study period & Propranolol & Topiramate \\
\hline Baseline & $9.36 \pm 4.55$ & $10.44 \pm 4.38$ \\
\hline 1st month & $8.50 \pm 4.21$ & $9.35 \pm 4.14$ \\
\hline 2nd month & $7.83 \pm 4.84$ & $8.50 \pm 4.21$ \\
\hline 3rd month & $6.21 \pm 4.20$ & $7.55 \pm 4.87$ \\
\hline 4th month & $5.60 \pm 4.28$ & $6.21 \pm 4.37$ \\
\hline 5th month & $4.34 \pm 4.18$ & $4.18 \pm 4.81$ \\
\hline 6th month & $3.12 \pm 4.07$ & $3.18 \pm 4.48$ \\
\hline $\begin{array}{l}\text { Significance } \\
\text { (Baseline - 6 months) }\end{array}$ & $<0.001$ & $<0.001$ \\
\hline $\begin{array}{l}\text { \%change } \\
\text { (Baseline - 6 months) }\end{array}$ & $63.5 \%$ & $70.2 \%$ \\
\hline
\end{tabular}

Table 2: Change in average duration (hours) of migraine for the patients who completed the study. $($ values $=$ Mean \pm SD $)$.

\begin{tabular}{|lll|}
\hline Study period & Propranolol & Topiramate \\
\hline Baseline & $15.92 \pm 9.73$ & $18.46 \pm 8.74$ \\
\hline 1st month & $14.10 \pm 9.21$ & $15.24 \pm 8.54$ \\
\hline 2nd month & $12.38 \pm 9.01$ & $12.12 \pm 8.00$ \\
\hline 3rd month & $10.55 \pm 9.65$ & $10.24 \pm 8.35$ \\
\hline 4th month & $8.29 \pm 8.60$ & $8.18 \pm 7.10$ \\
\hline 5th month & $6.25 \pm 8.50$ & $6.38 \pm 7.20$ \\
\hline 6th month & $5.62 \pm 8.06$ & $5.15 \pm 7.25$ \\
\hline $\begin{array}{l}\text { Significance } \\
\text { (Baseline- 6 months) }\end{array}$ & $<0.001$ & $<0.001$ \\
\hline $\begin{array}{l}\text { \%change } \\
\text { (Baseline- 6 months) }\end{array}$ & $55.5 \%$ & $75.7 \%$ \\
\hline
\end{tabular}

The average duration of migraine attacks is recorded in both the groups for six months, which shows the reduced average duration of migraine attacks to $75.7 \%$ with topiramate when compared to propranolol. P value $<0.001$ (Table 2).
The severity of migraine attacks was recorded in both the groups for six months which shows the reduced severity of pain by $58.7 \%$ with topiramate when compared to propranolol p value $<0.001$ (Table 3).

\section{Effect on body weight}

There was statistical significance between the two groups (Propranolol, Topiramate). In propranolol group patient experienced a gain of $0.53 \mathrm{~kg}$ after the completion of the treatment whose $\mathrm{p}$ value is $>0.05$. Which was not significant. Whereas Topiramate group had a loss of 2.94 $\mathrm{kg}$ after the completion of treatment. $\mathrm{P}$ value is $<0.05$ which was significant.

\section{Adverse effects}

Topiramate group has higher incidence of adverse effects like paresthesia, nausea, somnolence but none of them are serious. So there was no discontinuation of patients from the study.

The present study compared efficacy and safety of two drugs propranalol, and topiramate in migraine prophylaxis and concluded that topiramate had more side effects when compared to propranolol, but statistically topiramate decreased frequency, duration and severity of attacks as compared to propranolol.

Table 3: Change in severity of migraine attack using VAS score $(\%)$ for the patients who completed the study. $($ values $=$ Mean \pm SD $)$.

\begin{tabular}{|lll|}
\hline Study period & Propranolol & Topiramate \\
\hline Baseline & $77.60 \pm 13.33$ & $79.30 \pm 13.13$ \\
\hline 1st month & $70.58 \pm 13.20$ & $72.00 \pm 15.12$ \\
\hline 2nd month & $65.75 \pm 12.50$ & $63.18 \pm 18.74$ \\
\hline 3rd month & $60.29 \pm 20.12$ & $55.24 \pm 20.14$ \\
\hline 4th month & $53.30 \pm 21.80$ & $40.18 \pm 21.20$ \\
\hline 5th month & $35.57 \pm 21.90$ & $31.24 \pm 21.80$ \\
\hline 6th month & $27.10 \pm 25.22$ & $25.70 \pm 23.66$ \\
\hline $\begin{array}{l}\text { Significance } \\
\text { (Baseline - 6 months) }\end{array}$ & $<0.001$ & $<0.001$ \\
\hline $\begin{array}{l}\text { \%change } \\
\text { (Baseline - 6 months) }\end{array}$ & $49.6 \%$ & $58.77 \%$ \\
\hline
\end{tabular}

Table 4: All parameters comparison in each group at the end of $6 \mathrm{months.}$

\begin{tabular}{|lllllll|}
\hline Parameter & Group A & & \multicolumn{3}{c|}{ Group B } \\
\hline Weight(in kgs) & $56.15 \pm 10.67$ & $56.68 \pm 9.67$ & $0.53 \%$ & $57.50 \pm 13.01$ & $54.60 \pm 13.00$ & $2.94 \%$ \\
\hline $\begin{array}{l}\text { Frequency for } \\
\text { month }\end{array}$ & $9.36 \pm 4.55$ & $3.12 \pm 4.07$ & $63.5 \%$ & $10.44 \pm 4.38$ & $3.18 \pm 4.48$ & $70.2 \%$ \\
\hline $\begin{array}{l}\text { Duration of } \\
\text { Migraine }\end{array}$ & $15.92 \pm 9.73$ & $5.62 \pm 8.06$ & $55.5 \%$ & $18.46 \pm 8.74$ & $5.15 \pm 7.25$ & $75.7 \%$ \\
\hline Severity (VAS) & $77.60 \pm 13.33$ & $27.00 \pm 25.22$ & $49.6 \%$ & $79.30 \pm 13.13$ & $25.7 \pm 23.66$ & $58.7 \%$ \\
\hline
\end{tabular}


The reduction of frequency, duration, and severity of migraine with topiramate $25 \mathrm{mg}$ bd is $70 \%, 75 \%$ and $58 \%$ respectively. The reduction of frequency, duration, and severity of migraine with propranolol $40 \mathrm{mg}$ bd is $63 \%$, $55 \%$ and $49 \%$ at the end of six months.

\section{DISCUSSION}

Hundred patients were recruited in this study. The study period comprised of six months for each patient. One group of 50 patients (group A) were given propranolol in the dose of $40 \mathrm{mg}$ bd and other group of 50 patients (group B) were given topiramate $25 \mathrm{mg} \mathrm{BD}$. Before and after 6 months of treatment body weight, frequency (in days), duration (in hours) and severity (VAS) were measured. During this 6 months period patients were monitored every 4 weeks for adverse effects if any. Results were tabulated, comparison and significance were tested by paired student $\mathrm{T}$ test and their $\mathrm{P}$ value was calculated. In the present study topiramate had adverse effects like paresthesia, anxiety, tiredness and somnolence were frequently observed which is also a finding in Ahmed et al study.

The results in the present study proved that both propronolol and topiramate reduced frequency, severity, and duration of attacks $(\mathrm{p}<0.001)$ of migraine. There was no significant difference between propronolol and topiramate in reducing frequency, duration, and severity of migraine attacks. ${ }^{5}$ Both were found to be effective. However, topiramate is slightly more efficacious than propranolol. These results were consistent with the study of Ashtari et al. ${ }^{5}$ In the present study propronolol also significantly decreased frequency, duration and severity of migraine attacks with in the 6 months from $9.36 \pm 4.55$ to $3.12 \pm 4.07,15.92 \pm 9.73$ to $5.62 \pm 8.06,77.60 \pm 13.33$ to $27.10 \pm 25.22$ respectively. These results were consistent with study of Tonekaboni et al. ${ }^{6}$ In the present study topiramate had adverse effects like paresthesia, anxiety, tiredness and somnolence were frequently observed. These results were consistent with study of Shuaib et al. ${ }^{7}$ The most commonly prescribed drugs for migraine prophylaxis are beta blockers like propranolol and newer anti-epileptic drug like topiramate were included in our study.

\section{Limitations}

In this study the sample size was 100 , indicating that the study sample was small. Results for small studies were less reliable when compared to larger studies. Larger studies with more subjects produce narrow confidence of intervals (95-99\%) and so produce more precise results. It was difficult to distinguish between a real effect and a random variation in smaller studies. Severity of migraine attacks based on visual analogue scale (VAS) is difficult to get from the migraine patients. This study was done only with doses of propranolol $40 \mathrm{mg}$ and topiramate $25 \mathrm{mg}$. Varying doses and dose titrated effects comparison was not done in this study.

\section{CONCLUSION}

This study demonstrated that both propranolol and topiramate could significantly reduce migraine headache frequency, duration and intensity. However, compared with propranolol topiramate showed slightly better results. The reduction of frequency, duration, and severity of migraine with Topiramate $25 \mathrm{mg}$ bd is $70 \%, 75 \%$ and $58 \%$ respectively. The reduction of frequency, duration, and severity of migraine with propranolol $40 \mathrm{mg}$ bd is $63 \%$, $55 \%$ and $49 \%$ at the end of six months. This shows topiramate was slightly more efficacious than propranolol.

\section{Funding: No funding sources}

Conflict of interest: None declared

Ethical approval: The study was approved by the Institutional Ethics Committee

\section{REFERENCES}

1. Dahlof C, Linde M. One-year prevalence of migraine in Sweden: a population-based study in adults. Cephalalgia 2001;21:664-71.

2. Headache classification subcommittee of the International Headache Society. The international classification of headache disorders: 2nd edition. Cephalalgia. 2004;24(1):9-160.

3. Eriksen M, Thomsen L, Andersen I, Nazim F, Olesen J. "Clinical characteristics of 363 patients with familial migraine with aura". Cephalalgia 2004;24:564-75.

4. Meyer J, Thornby J, Ceawford K, Rauch G. Reversible cognitive decline accompanies migraine and cluster headache. Headache. 2000;40:638-46.

5. Ashtari F, Shaygannejad V, Akbari M. A doubleblind, randomized trial of low-dose topiramate vs propranolol in migraine prophylaxis. Acta Neurologica Scandinav. 2008;118(5):301-5.

6. Tonekaboni SH, Ghazavi A, Fayyazi A, Khajeh A, Taghdiri MM, Gorji FA, Azarghashb E. Prophylaxis of childhood migraine: topiramate versus propranolol. Iran J Child Neurol. 2013;7(1):9.

7. Shuaib A, Ahmed F, Muratoglu M, Kochanski P. Topiramate in migraine prophylaxis: a pilot study [abstract]. Cephalalgia 1999;19:379-80.

Cite this article as: Rajkumar K, Kumar PA. A prospective randomized single blind study to compare the safety and efficacy of propronolol and topiramate in migraine prophylaxis. Int J Basic Clin Pharmacol 2021;10:425-8. 